\title{
Conversion disorder in childhood-diagnosed too late, investigated too much?
}

\author{
P M Leary MD FCP(SA)
}

J R Soc Med 2003;96:436-438

Conversion disorder is defined in the Diagnostic and Statistical Manual of Mental Disorders $(D S M-I V)^{1}$ as a condition in which symptoms and deficits in voluntary motor function suggest a neurological or other physical condition which is in fact not present. Child psychiatrists have reported a prevalence of $1-3 \%$ in the patients they see. ${ }^{2,3}$ Among new outpatients at a paediatric neurology unit in the west of England the prevalence is closer to $10 \%$. These cases place considerable demands on consulting time and diagnostic resources. In this paper a case is made for early recognition and for management by the general paediatric team.

\section{ILLUSTRATIVE HISTORIES}

\section{Case 1}

A boy of 12 was referred for investigation of gait disorder. There was a five-month history of nausea, weakness, inverted sleeping pattern and inability to extend the right elbow. He had not attended school since the onset of his illness and had undergone extensive investigation at a district general hospital. He was noted to walk with a bizarre staggering gait which on close inspection could be seen to be carefully coordinated. His right elbow was rendered unmoveable by sustained palpable contraction of both biceps and triceps muscles. Systematic detailed clinical examination showed no neurological abnormality. A tentative diagnosis of conversion disorder was made and the boy's background was explored. He had experienced scholastic difficulties at primary school. Shortly before the onset of his illness he had moved with his peer group to a secondary school with high academic expectations of pupils. He had not been able to achieve these and the teacher of his favourite subject had humiliated him by rejecting class work he had done and throwing his workbook on the floor. Transfer to another school was unacceptable, as he did not wish to be separated from his friends. Psychotherapy was instituted with gradual improvement. However, ten months elapsed before he was confident and well enough to return to school.

Bristol Royal Hospital for Children, Bristol, UK

Correspondence to: Professor P M Leary, Institute of Child Health, Directorate of Children's Services, 6th Floor, UBHT Education Centre, Upper Maudlin Street, Bristol BS2 8AE, UK

E-mail: mickleary@blueyonder.co.uk

\section{Case 2}

This boy was referred at age 10 as a case of juvenile myasthenia gravis. For five weeks he had been unable to open his eyes and the consequent 'blindness' had stopped him attending school. On examination it was immediately evident that his eyes were being held firmly closed, to the extent that they could not be prised open to inspect the cornea and conjunctiva. On detailed physical examination no other abnormality was found. In the hospital ward it was noted that he did not walk into furniture and, left alone, would follow football matches on the television screen. Discussion with his mother revealed that there were scholastic difficulties. He was the local village football star and had been selected for a junior football academy. After a trial period at this institution he had been rejected as not good enough. Shortly after this setback he had been blamed for his team's defeat in a needle match and from that day he had been unable to open his eyes. In hospital he was provided with a pair of dark glasses which permitted eye opening without loss of face in front of his peers. He was medically boarded from playing football for the rest of the season. An approach was made to his school headteacher and extra tuition was arranged in his weaker subjects. Within two weeks, eye-opening had become normal and he had returned to full active life.

\section{CLINICAL PROFILE}

During childhood, conversion disorder occurs most commonly in the 10-15 year age bracket and the condition is roughly twice as common in girls as it is in boys. ${ }^{4}$ In most cases symptoms date from a minor illness or injury. Rigid obsessional personality trait, ${ }^{5}$ an anxiety state or depression ${ }^{6}$ and previous sexual abuse ${ }^{7}$ all predispose to development of a conversion disorder. Environmental factors include domestic stress, feelings of parental rejection, poor intrafamilial communication, unresolved grief ${ }^{8}$ and unhappiness at school. ${ }^{9}$ Illness and disability can be amplified and prolonged when the patient has an ally who champions the notion that symptoms are due to organic disease. ${ }^{10}$ An ally of this nature may be a family member or a healthcare professional.

Symptoms are most commonly motor-paralysis, gait disturbance, incoordination, tremor, loss of speech. 
Sensory manifestations include paraesthesia, intractable pain, tunnel vision and blindness. Incapacitating headache, unremitting fatigue and pseudoseizures are other common presenting features. Allowance must be made for cultural variation in the mode of presentation. A study in Pakistan ${ }^{11}$ showed 'unresponsiveness' as the commonest presenting feature in conversion disorder, and in certain areas of Southern Africa a state of apparent agitated dementia is well recognized.

In the great majority of cases early diagnosis can be achieved by detailed physical examination and the identification of incongruities. Reciprocal contraction is palpable during attempts to use apparently paralysed muscle groups and normal tendon reflexes can be elicited in the face of flaccidity. Abnormal gaits are bizarre and do not conform to those seen in children with diplegia, athetoid cerebral palsy, cerebellar dysfunction or hip disorder. Sensory loss does not conform to dermatome or glove-andstocking distribution. Diplopia is present in all directions and may persist despite occlusion of one eye. In apparent blindness, collisions and injuries do not occur. Short-lived remissions may be noted when the patient is alone and when sudden 'emergencies' arise such as need for the toilet or for sustenance. Pseudoseizures occur only in the waking state and in company. They may be longlasting and commonly include repetitive pelvic thrusting movements which are never seen in true seizures. Urinary incontinence is not a feature.

\section{NEUROPSYCHOLOGICAL MECHANISMS}

The results of some recent neurobiological studies are of note. In a controlled study, Roelofs et al. ${ }^{12}$ reported that adults with conversion disorders had abnormally long motor reaction times but normal duration motor responses. This is the reverse of what is found in organic motor disorder and implies impairment in motor task initiation. Imaging techniques have been used to identify the areas of brain involved. With positron emission tomography in a patient with longstanding conversion disorder (leg paralysis), Marshall et al. ${ }^{13}$ noted activation of two distinct areas of prefrontal cortex; and Halligan et al., ${ }^{14}$ in a man with hypnotically induced paralysis of the left leg, observed selective activation in the same areas when the individual attempted to move his leg. Electrophysiological studies indicate that these parts of the brain - the right orbitofrontal and anterior cingulate areas - are involved in motor inhibition. Conversion disorders and hypnotic paralysis may have neurophysiological mechanisms in common. Using single photon emission computerized tomography in seven individuals with unilateral sensorimotor conversion disorder Vuilleumier et al. ${ }^{15}$ found consistent decreases in regional blood flows in the contralateral thalamus and basal ganglia.
These changes were no longer evident after recovery. The findings in this study suggest that in conversion disorder there is a transitory functional disorder in striatothalamocortical circuits, which control sensory and voluntary motor function.

\section{MANAGEMENT}

Fear of misdiagnosis with consequent litigation can delay the positive diagnosis of conversion disorder. Such anxiety can lead to gross overinvestigation and 'medicalization' of the disorder with delay in instituting effective treatment. Refusal by parents to accept the absence of organic disease may be another major stumbling-block to effective management. Such refusal often goes with denial of any domestic tensions or disharmony and with anger directed at medical personnel-attitudes that can greatly hamper the institution of appropriate therapy, as can misguided support for any opposition to treatment expressed by the patient.

Intervention begins with an acknowledgement that the young person has a real illness which has seriously disrupted normal patterns of living. The presenting disability should be regarded as a symptom reflecting unconscious conflict. Wherever possible the child should be admitted to hospital, preferably with some limitations on parental access. This may prove difficult in view of current ward practice but it can often be achieved by reference to the child's age and normal level of independence and by firm reassurance that the nature of the illness does not justify a 24-hour parental bedside vigil. In many instances this will serve to remove the patient from the conflict that led to the illness and will also lessen the effects of parental lack of cooperation if this is an issue. Special investigations should be limited to the minimum compatible with exclusion of organic disorder. The patient's primary gain from the illness should be identified at an early stage-e.g. release from a stressful school situation. The therapeutic programme should be tailored to allow the individual to recover without loss of face in front of peers and family. It should be instituted without delay.

Therapeutic success can be achieved through several different approaches. Probably the most effective is a graded physiotherapy programme linked to a reward system and directed by an empathic physiotherapist, as reported by Bragier and Venning. ${ }^{16}$ This can be provided within the setting of children's hospital wards under the supervision of general paediatricians. If the regimen is started early in the illness, recovery can be achieved in most cases without recourse to the overburdened child psychiatry and psychology services. Good results have also been achieved with behaviour therapy (both positive and negative reinforcement ${ }^{17}$ ), psychotherapy, ${ }^{18} \operatorname{psychoanalysis}^{19}$ and hypnosis, ${ }^{20,21}$ but these are time-consuming and call for 
special training. They should be reserved for complex cases that prove unresponsive to short-term admission and graded physiotherapy. When depression and or anxiety are prominent features, antidepressant and/or anxiolytic medication should be prescribed.

\section{PROGNOSIS}

Follow-up studies indicate eventual full recovery in from $85 \%$ to $97 \%$ of children. With early recognition of the nature of the condition and prompt intervention, some recover within a few weeks or even days. ${ }^{22,23}$ In Turgay's study $^{23}$ only 3 out of 89 patients took longer than four weeks to recover. Favourable prognostic features are recent onset of symptoms, monosymptomatic manifestation and a good premorbid personality. ${ }^{22}$ The outlook is less good when symptoms have been present for a long time before institution of appropriate therapy, ${ }^{24}$ when conduct disorder has preceded the illness, ${ }^{22}$ when there is a history of sexual abuse, when symptoms are multiple ${ }^{25}$ and when an anxiety state or clinical depression is present.

\section{CONCLUSION}

Every general paediatrician will see cases of conversion disorder, and successful outcomes depend greatly on early recognition. Investigations should be limited to the minimum compatible with exclusion of organic disease, since exhaustive investigation will medicalize the problem in the eyes of parents and patient and can delay appropriate treatment. Admission to hospital is usually effective if the child is thus exposed to a positive therapeutic programme directed by an experienced physiotherapist and reinforced by the nursing team. The provision of such a service should be within the capabilities of general paediatricians and district general hospitals.

\section{REFERENCES}

1 American Psychiatric Association. Diagnosis and Statistical Manual of Mental Disorders, 4th edn. Washington, DC: APA, 1994

2 Goodyer I. Hysterical conversion reactions in childhood. J Child Psychol Psychiatry 1981;22:179-88

3 Gelder M, Gath D, Mayou R, Cowen P, eds. Oxford Textbook of Psychiatry. Oxford: Oxford University Press, 1996:353

4 Anon. Neurological conversion disorders in childhood. Lancet 1991;337: 889-90
5 Wynick S, Hobson RP, Jones RB. Psychogenic disorders of vision in childhood ('visual conversion reactions'): perspective from adolescence: a research note. J Child Psychol Psychiatry 1997;38:375-9

6 Pehlivanturk B, Unal F. Conversion disorder in children and adolescents: clinical features and comorbidity with depressive and anxiety disorders. Turk J Pediatr 2000;42:132-7

7 Harden CL. Pseudoseizures and dissociative disorders: a common mechanism involving traumatic experiences. Seizures 1997;6:151-5

8 Maloney MJ. Diagnosing hysterical conversion reactions in children. J Pediatr 1980;97:1016-20

9 Binzer M, Eisemann M. Childhood experiences and personality traits in patients with motor conversion symptoms. Acta Psychiatr Scand 1998;98:288-95

10 Leslie SA. Diagnosis and treatment of hysterical conversion reactions. Arch Dis Child 1988;63:506-11

11 Syed EV, Aliq R, Effendi S, Mehmud S. Conversion disorder: difficulties in diagnosis using DSM-IV/ICD-10. J Pak Med Assoc 2001; 51:143-5

12 Roelofs K, Van Gallen G, Keÿers G, Hoogduim C. Motor initiation and execution in patients with conversion paralysis. Acta Psychol 2002;110:21-34

13 Marshall JC, Halligan PW, Fink GR, Wade DT. Frackowiak RSJ. The functional anatomy of a hysterical paralysis. Cognition 1997;64:B1-8

14 Halligan PW, Alhwal BSS, Oakley DA, Frackowiak RS. Imaging hypnotic paralysis: implications for conversion hysteria. Lancet 2000; 355:986-7

15 Vuilleumier P, Chicherio C, Assal F, Schwartz S, Slosman D, Landis T. Functional neuro-anatomical correlates of hysterical sensori-motor loss. Brain 2001;124:1077-90

16 Bragier DK, Venning HE. Conversion disorders in adolescents: A practical approach to rehabilitation. BrJ Rheumatol 1997;36:594-8

17 Campo JV, Negrini BJ. Case study: negative reinforcement and behavioural management of conversion disorder. J Am Acad Child Adolesc Psychiatry 2000;39:787-90

18 Silver FW. Management of conversion disorder. Am J Phys Med Rehab 1996;75:134-40

19 Mulrod B. A 9-year-old with conversion disorder successfully treated with psychoanalysis. Inst J Psychoanal 2002;83:623-31

20 Bloom PB. Treating adolescent conversion disorders: are hypnotic techniques reusable? Int J Clin Exp Hypnosis 2001;49:243-56

21 Moene FC, Spinhoven P, Hoogduin KA, Van Dyck R. A randomised controlled clinical trial on the additional effect of hypnosis in a comprehensive treatment programme for in-patients with conversion disorder of the motor type. Psychother Psychosom 2002;71:66-76

22 Pehlivanturk B, Unal F. Conversion disorder in children and adolescents. A four year follow up study. J Psychosom Res 2002;52: 187-91

23 Turgay A. Treatment outcome for children and adolescents with conversion disorder. Can J Psychiatry 1990;35:585-9

24 Hafeiz HB. Hysterical conversion: a prognostic study. Br J Psychiatry 1980;136:548-51

25 Murase S, Sugiyama T, Iskii T, Wakako R, Ohta T. Polysymptomatic conversion disorder in childhood and adolescence in Japan. Early manifestation or incomplete form of somatization disorder? Psychother Psychosom 2000;69:132-6 